\title{
28 Research Square \\ Production of Indole-3-Acetic Acid: A White Biotechnology for Weed Biocontrol
}

Sakaoduoen Bunsangiam

Kasetsart University

Nutnaree Thongpae

Kasetsart University

Savitree Limtong

Kasetsart University

Nantana Srisuk ( $\square$ fscints@ku.ac.th )

Kasetsart University

\section{Research Article}

Keywords: IAA, indole-3-acetic acid, OFAT, biotechnology

Posted Date: March 5th, 2021

DOI: https://doi.org/10.21203/rs.3.rs-263289/v1

License: (c) (1) This work is licensed under a Creative Commons Attribution 4.0 International License. Read Full License 


\section{Abstract}

Indole-3-acetic acid (IAA) is the most common plant hormone of the auxin class and regulates various plant growth processes. The present study investigated IAA production by the basidiomycetous yeast Rhodosporidiobolus fluvialis DMKU-CP293 using the one-factor-at-a-time (OFAT) method and response surface methodology (RSM). IAA production was optimized in shake-flask culture using a cost-effective medium containing $4.5 \%$ crude glycerol, $2 \%$ CSL and $0.55 \%$ feed-grade L-tryptophan. The optimized medium resulted in a 3.3-fold improvement in IAA production and a 3.6-fold reduction in cost compared with those obtained with a non-optimized medium. Production was then scaled up to a 15-L bioreactor and to a pilot-scale (100-L) bioreactor based on the constant impeller tip speed $\left(\mathrm{V}_{\text {tip }}\right)$ strategy. By doing so, IAA was successfully produced at a concentration of $3,569.32 \mathrm{mg} / \mathrm{L}$ at the pilot scale. To the best of our knowledge, this is the first report of pilot-scale IAA production by microorganisms. In addition, we evaluated the effect of crude IAA on weed growth. The results showed that weed (Cyperus rotundus $\mathrm{L}$.) growth could be inhibited by $50 \mathrm{mg} / \mathrm{L}$ of crude IAA. IAA therefore has the potential to be developed as a herbicidal bioproduct to replace the chemical herbicides that have been banned in various countries, including Thailand.

\section{Introduction}

The global population and the corresponding food demand have been increasing annually in the past decades, and improvements in crop production are therefore needed. There is a high risk of crop yield loss, approximately $34 \%$ of which per year is caused by weeds ${ }^{1,2}$. Synthetic herbicides are widely used to control weeds, but their intensive use causes environmental pollution, the accumulation of harmful residues in soil and water resources, mammalian toxicity, and the evolution of herbicide resistance ${ }^{3,4}$. Due to human health concerns, hazardous herbicides such as paraquat, glyphosate and chlorpyrifos have already been banned in many countries worldwide. To minimize the use of toxic chemical herbicides, weed control using bioproducts called bioherbicides ${ }^{5}$ produced by eco-friendly technology will provide great benefits to both farmers and consumers.

Indole-3-acetic acid (IAA) is the most common auxin-class phytohormone and plays vital roles in plant growth and plant development processes, such as cell division, cell expansion, cell differentiation and fruit development ${ }^{6,7}$. IAA homeostasis is important for maintaining the hormonal balance at an optimum level suitable for normal plant growth and development. However, high levels of IAA can exert an inhibitory effect on plant physiological processes ${ }^{8}$. Several studies have reported that IAA at high concentrations inhibits seed germination and plant growth ${ }^{9-12}$. The inhibition scenario is caused by ethylene production due to aminocyclopropane-1-carboxylic acid synthase (ACC synthase) activity stimulated by high levels of auxin accumulation, which results in an ethylene burst that causes plant growth abnormalities and senescence. A more important factor implicated in growth inhibition and the actual phytotoxic response to auxins is the overproduction of abscisic acid (ABA) ${ }^{13}$. This is why IAA is naturally synthesized at low levels in plants or derived from plant-associated microbes. 
Various microorganisms have shown the ability to produce IAA, such as bacteria, actinomycetes, fungi or yeast ${ }^{14-21}$. To produce safe agricultural products and reduce the use of chemical herbicides, potential IAA-producing microbes are attractive for use as producers for further commercial-scale IAA production. Yeast has been suggested to be a potent biotechnological microorganism that utilizes various substrates for growth and metabolite production. Our previous research showed that the basidiomycetous yeast Rhodosporidiobolus fluvialis DMKU-CP293 was a strong IAA producer ${ }^{22}$. However, little information on the optimization of yeast IAA production has been reported ${ }^{23,24}$. It is therefore of interest to optimize the IAA production medium for $R$. fluvialis DMKU-CP293. In biotechnology processes, the medium composition is of critical importance due to its impact on product concentration and production cost. In addition to the medium composition, which includes carbon sources, nitrogen sources, growth factors and L-tryptophan (a precursor of IAA biosynthesis), $\mathrm{pH}$ and temperature also affect microbial IAA production ${ }^{15,24-26}$. The optimization strategies employed in the present work were the one-factor-at-atime (OFAT) and response surface methodology (RSM) approaches. OFAT, a traditional strategy to economically optimize bioproduct production, involves varying one factor while keeping the other factors constant. This approach is the simplest to implement and primarily helps in the selection of significant parameters affecting IAA yield. Alternatively, a statistical strategy for the simultaneous study of several factors influencing the production process at the same time, such as factorial experimental design and RSM, can be used.

Microbial IAA production may be a white biotechnology that could be employed to replace chemical IAA synthesis, which is expensive, unstable, and performed under extreme conditions using highly toxic substances ${ }^{27}$. Although microbial IAA production has been reported over the last decade, knowledge about large-scale IAA production in bioreactors is still lacking. Generally, prior to scaling up a bioprocess, the parameters are initially optimized through small-scale batch cultivations. However, those obtained parameters might not be transferable directly from small batch to large-scale fermentations. Therefore, an optimization process in a large-scale bioreactor is necessary to achieve high-yield IAA production. In this work, we aim to identify the optimal cost-effective medium and conditions for the pilot-scale production of IAA by the phylloplane yeast $R$. fluvialis DMKU-CP293 using OFAT and RSM. Furthermore, we also assess the efficacy of yeast IAA on weed suppression. We believe this study provides a reasonable bioprocess development approach for realizing the production of bioproducts to replace toxic substances for use in the agricultural sector.

\section{Results}

\section{Optimization of IAA production by Rhodosporidiobolus fluvialis DMKU-CP293}

\section{One-factor-at-a-time (OFAT)}

When grown in the base medium (YPD broth) supplemented with 0.1\% L-tryptophan, $R$. fluvialis DMKUCP293 produced the maximum IAA level $(1,061.97 \pm 4.29 \mathrm{mg} / \mathrm{L})$ after 5 days of incubation (Fig. 1). To 
achieve maximum production, a one-factor-at-a-time (OFAT) approach was first applied. To select an appropriate carbon source, glucose was replaced by galactose, glycerol, lactose, sucrose, and xylose in turn. The highest IAA production $(1,217.25 \pm 39.66 \mathrm{mg} / \mathrm{L})$ was observed after 2 days of cultivation when glycerol was used (Fig. 1). To achieve low-cost IAA production, crude glycerol, which is a major byproduct of the biodiesel production process, was chosen as an alternative low-cost substrate to replace laboratory-grade glycerol. Fermentation performed with crude glycerol showed a similar level of IAA production with only one additional day of incubation $(1,048.91 \pm 12.69 \mathrm{mg} / \mathrm{L}$ at 3 days of cultivation) compared with that required for pure glycerol (Fig. 2a). Crude glycerol was thus used in the subsequent studies.

To further reduce fermentation costs, a low-cost medium component was screened, and feed-grade Ltryptophan was used to replace analytical-grade L-tryptophan at the same concentration $(0.1 \%)$. Figure $2 \mathrm{~b}$ shows that a similar IAA concentration was obtained when the medium was supplemented with feed-grade L-tryptophan and analytical-grade L-tryptophan. Low-cost feed-grade L-tryptophan was therefore used in subsequent studies. The effect of temperature on IAA production was preliminarily studied between $30^{\circ} \mathrm{C}$ and $35^{\circ} \mathrm{C}$. The results showed that $R$. fluvialis DMKU-CP293 produced a similar level of IAA production between $30^{\circ} \mathrm{C}$ and $34^{\circ} \mathrm{C}$, but a significant decrease $(p<0.05)$ in IAA production was observed at $35^{\circ} \mathrm{C}$ (data not shown). Therefore, subsequent IAA production was performed at $34^{\circ} \mathrm{C}$.

The effect of the crude glycerol concentration was studied within a range of 0 to $5 \%(\mathrm{w} / \mathrm{v})$. The optimal IAA concentration was detected at $871.11 \pm 1.84 \mathrm{mg} / \mathrm{L}$, when $3.5 \%$ crude glycerol was used. No significant difference $(p<0.05)$ in IAA production was found when $3 \%$ and $3.5 \%$ crude glycerol were added to the production medium (Fig. 3a). A crude glycerol concentration of $3 \%$ was therefore selected for IAA production by $R$. fluvialis DMKU-CP293. Figure $3 \mathrm{~b}$ indicates the results of the nitrogen source optimization experiment. $\mathrm{NH}_{4} \mathrm{Cl},\left(\mathrm{NH}_{4}\right)_{2} \mathrm{SO}_{4},\left(\mathrm{NH}_{4}\right)_{2} \mathrm{HPO}_{4}, \mathrm{KNO}_{3}, \mathrm{NaNO}_{3}, \mathrm{NH}_{4} \mathrm{NO}_{3}$, peptone, tryptone, urea and corn steep liquor (CSL) were individually supplemented at $2 \%$ into the production medium containing $3 \%$ crude glycerol as the carbon source. The results showed that maximum IAA production $(919.93 \pm 6.30$ $\mathrm{mg} / \mathrm{L}$ ) was achieved when $2 \% \mathrm{CSL}$ was supplied as the nitrogen source under the conditions studied (Fig. 3c).

In addition to carbon and nitrogen sources (Fig. 3a-C), growth factors were also investigated (Fig. 3d). Technical-grade yeast extract was chosen for further study because it is less expensive than beef extract, and these two growth factors resulted in similar amounts of IAA production $(875.78 \pm 33.97 \mathrm{mg} / \mathrm{L}$ and $846.25 \pm 77.24 \mathrm{mg} / \mathrm{L}$ when beef extract and technical-grade yeast extract were used, respectively). Figure $3 e$ indicates that a high IAA concentration was obtained when the production medium was supplemented with $1 \%$ technical-grade yeast extract.

Tryptophan is generally considered a precursor for IAA production. In this study, the L-tryptophan concentration was therefore optimized. The results showed that IAA production increased from $939.84 \pm$ $4.02 \mathrm{mg} / \mathrm{L}$ to $2,432.61 \pm 82.85 \mathrm{mg} / \mathrm{L}$ when the L-tryptophan concentration increased from $0.1-0.6 \%$; 
however, the IAA concentration did not significantly $(p<0.05)$ increase when $0.7 \%$ L-tryptophan was used $(2,477.86 \pm 42.34 \mathrm{mg} / \mathrm{L})$ (Fig. 3f).

\section{Response Surface Methodology (RSM)}

The important factors obtained from the preliminary OFAT screening were applied to the RSM approach. Four factors, crude glycerol $\left(X_{1}\right), \operatorname{CSL}\left(X_{2}\right)$, technical-grade yeast extract $\left(X_{3}\right)$, and feed-grade L-tryptophan $\left(X_{4}\right)$, were optimized through a central composite design (CCD), which is the most commonly used design for second-order models. CCD permits a lack-of-fit test to be performed from fewer experiments and also provides rotatability and orthogonality ${ }^{28,29}$. A total of 21 experiments were conducted to elucidate the effects of factors and their interactions on IAA production. A CCD simulation was carried out to predict the quadratic model that was most suitable to describe the relationship between the factors and responses. Regression was performed to fit the response function to the experimental data and resulted in models represented by the following equations (1):

$\operatorname{IAA}(\mathrm{mg} / \mathrm{L})=1081.6-150.86 \mathrm{X}_{1}-886.02 \mathrm{X}_{2}-849.91 \mathrm{X}_{3}+30.86 \mathrm{X}_{4}-410.25 \mathrm{X}_{1} \mathrm{X}_{2}+13.72 \mathrm{X}_{1} \mathrm{X}_{3}-820.25 \mathrm{X}_{1} \mathrm{X}_{4}$ $-7.59 X_{2} X_{3}-47.67 X_{2} X_{4}-527.25 X_{3} X_{4}+38.82 X_{1}^{2}+281.24 X_{2}^{2}+322.06 X_{3}^{2}-443.47 X_{4}^{2}(1)$

where IAA (mg/L) represents the predicted IAA production response; $X_{1}$ is the crude glycerol concentration, $X_{2}$ is the CSL concentration, $X_{3}$ is the technical-grade yeast extract concentration and $X_{4}$ is the feed-grade L-tryptophan concentration.

The statistical analysis of factor significance was described by the analysis of variance (ANOVA) results shown in Table 1. The determination coefficient $\left(R^{2}\right)$, correlation, and model significance $(p$-value) were used to analyze the fit of the model. The model obtained in this work showed a coefficient value $\left(R^{2}\right)$ of 0.9429 for IAA production, indicating that only $5.71 \%$ of the total variation was not explained by the model. The adjusted $R^{2}$ was 0.8096 , indicating good agreement between the obtained and predicted values for the output response. The model significance ( $F$-value) indicating data variation around the mean was also measured. The probability value of the model ( $p$-value prob $>F$ ) was less than 0.05 , implying that the model could be considered to be significant. In addition, the probability value also indicated that the present model predicted the experimental results well. The optimum values of the variables were determined to maximize IAA production by $R$. fluvialis DMKU-CP293. From the regression model, contour plots assisted in understanding the effect as well as the interactions of the four factors, i.e., crude glycerol, CSL, technical-grade yeast extract and feed-grade L-tryptophan. Response surface plots were drawn to illustrate the pairwise combinations of the four variables (Fig. 4). According to Fig. 4 (a-f), high levels of crude glycerol and feed-grade L-tryptophan and low levels of CSL and technical-grade yeast extract enhanced IAA yield. A low level of technical-grade yeast extract was found to increase IAA production, as shown in Fig. 3e. However, the summary of the criteria set for the optimization run obtained from the CCD showed that yeast extract could be omitted from the culture because the optimized level of yeast extract provided was "-0.55" (Fig. S1c). 
Table 1

Regression analysis quadratic model of CCD

\begin{tabular}{|c|c|c|c|c|c|}
\hline Source & $\begin{array}{l}\text { Sum of } \\
\text { squares }\end{array}$ & df & $\begin{array}{l}\text { Mean } \\
\text { square }\end{array}$ & Fvalue & $\underset{F}{p \text {-value Prob }>}$ \\
\hline Model & $2.440 \mathrm{E}+007$ & 14 & $\begin{array}{l}1.743 \mathrm{E}+ \\
006\end{array}$ & 7.07 & 0.0121 \\
\hline $\mathrm{X}_{1}$-Crude glycerol & 1.287E + 005 & 1 & $\begin{array}{l}1.287 \mathrm{E}+ \\
005\end{array}$ & 0.52 & 0.4970 \\
\hline $\mathrm{X}_{2}-\mathrm{CSL}$ & $4.441 \mathrm{E}+006$ & 1 & $\begin{array}{l}4.441 \mathrm{E}+ \\
006\end{array}$ & 18.02 & 0.0054 \\
\hline $\begin{array}{l}X_{3} \text {-Technical-grade yeast } \\
\text { extract }\end{array}$ & $9.865 E+006$ & 1 & $\begin{array}{l}9.865 E+ \\
006\end{array}$ & 40.04 & 0.0007 \\
\hline $\mathrm{X}_{4}$-Feed-grade L-tryptophan & 5385.54 & 1 & 5385.54 & 0.022 & 0.8873 \\
\hline $\mathrm{x}_{1} \mathrm{X}_{2}$ & $5.577 \mathrm{E}+005$ & 1 & $\begin{array}{l}5.577 \mathrm{E}+ \\
005\end{array}$ & 2.26 & 0.1832 \\
\hline$x_{1} x_{3}$ & 1504.85 & 1 & 1504.85 & $\begin{array}{l}6.108 \mathrm{E}- \\
003\end{array}$ & 0.9402 \\
\hline $\mathrm{X}_{1} \mathrm{X}_{4}$ & $2.230 E+006$ & 1 & $\begin{array}{l}2.230 \mathrm{E}+ \\
006\end{array}$ & 9.05 & 0.0238 \\
\hline$x_{2} x_{3}$ & 461.11 & 1 & 461.11 & $\begin{array}{l}1.871 \mathrm{E}- \\
003\end{array}$ & 0.9669 \\
\hline $\mathrm{X}_{2} \mathrm{X}_{4}$ & 7528.89 & 1 & 7528.89 & 0.031 & 0.8670 \\
\hline $\mathrm{X}_{3} \mathrm{X}_{4}$ & $2.224 \mathrm{E}+006$ & 1 & $\begin{array}{l}2.224 \mathrm{E}+ \\
006\end{array}$ & 9.03 & 0.0239 \\
\hline $\mathrm{X}_{1}{ }^{2}$ & 22521.91 & 1 & 22521.91 & 0.091 & 0.7726 \\
\hline$x_{2}^{2}$ & $1.182 E+006$ & 1 & $\begin{array}{l}1.182 \mathrm{E}+ \\
006\end{array}$ & 4.80 & 0.0710 \\
\hline$x_{3}{ }^{2}$ & $1.550 E+006$ & 1 & $\begin{array}{l}1.550 \mathrm{E}+ \\
006\end{array}$ & 6.29 & 0.0460 \\
\hline$x_{4}^{2}$ & $2.939 E+006$ & 1 & $\begin{array}{l}2.939 \mathrm{E}+ \\
006\end{array}$ & 11.93 & 0.0136 \\
\hline Residual & $1.478 E+006$ & 6 & $\begin{array}{l}2.464 \mathrm{E}+ \\
005\end{array}$ & & \\
\hline Lack of Fit & $8.030 E+005$ & 2 & $\begin{array}{l}4.015 E+ \\
005\end{array}$ & 2.38 & 0.2087 \\
\hline Pure Error & $6.753 E+005$ & 4 & $\begin{array}{l}1.688 \mathrm{E}+ \\
005\end{array}$ & & \\
\hline
\end{tabular}




\begin{tabular}{|l|lll}
\hline Source & $\begin{array}{l}\text { Sum of } \\
\text { squares }\end{array} \quad$ df & $\begin{array}{l}\text { Mean } \\
\text { square }\end{array}$ & $F$-value \\
\hline$F$
\end{tabular}

$R^{2}=0.9429$, Adjusted $R^{2}=0.8096$

To confirm the ability of the model to predict the maximum response, triplicate sets of experiments were performed using the optimized medium composition, $4.5 \%$ crude glycerol, $2 \% \mathrm{CSL}$ and $0.55 \%$ feed-grade L-tryptophan, with incubation at $34^{\circ} \mathrm{C}$ for 5 days on an orbital shaker at $200 \mathrm{rpm}$. These sets of conditions were also used to validate and predict the responses using the model equation. The observed IAA concentration $(3,514.44 \pm 52.37 \mathrm{mg} / \mathrm{L})$ was close to the predicted value $(3,474.36 \mathrm{mg} / \mathrm{L})$, confirming the validity and adequacy of the model. Using the optimized medium, IAA production was increased up to 3.3-fold compared with that obtained using unoptimized medium. In addition, IAA productivity and IAA yield at the end of 5 days of fermentation were $29.29 \mathrm{mg} / \mathrm{L} / \mathrm{h}$ and $0.65 \mathrm{mg} \mathrm{IAA} / \mathrm{mg} \mathrm{L-tryptophan,}$ respectively.

\section{IAA production in the pilot-scale $100-\mathrm{L}$ bioreactor}

To achieve high-level IAA production in the bioreactor, the inoculum size and agitation speed were preliminarily investigated in a 2-L laboratory-scale bioreactor. The inoculum size $(5 \%-20 \%)$ and agitation speed (200 rpm, $300 \mathrm{rpm}$, and $400 \mathrm{rpm}$ ) were varied, and the aeration rate was fixed at $1 \mathrm{vvm}$. The optimal conditions were $10 \%$ inoculum size, $400 \mathrm{rpm}$ agitation and $1 \mathrm{vvm}$ aeration (data not shown). The highest IAA concentration, $2,870.15 \pm 11.38 \mathrm{mg} / \mathrm{L}$ (equivalent to an IAA yield of $0.51 \mathrm{mg} \mathrm{IAA} / \mathrm{mg} \mathrm{L}$ tryptophan), was achieved after 2 days at $34^{\circ} \mathrm{C}$ (Fig. 5a). IAA production was scaled up into a 15-L bioreactor with the same cultivation medium and conditions used in the 2-L bioreactor, and the maximum IAA level, $3,468.17 \pm 66.61 \mathrm{mg} / \mathrm{L}$ (equivalent to an IAA yield of $0.68 \mathrm{mg}$ IAA/mg L-tryptophan), was obtained after 3 days (Fig. 5b). To further scale up IAA production, a 100-L pilot-scale bioreactor was set up with a constant impeller tip speed $\left(\mathrm{V}_{\text {tip }}\right)$. Since the agitation rate was scaled based on the $\mathrm{V}_{\text {tip }}$ (proportional to $N D_{1}$, where $N$ is the agitation speed and $D_{1}$ is the impeller diameter), it was expected that the broth viscosity would remain similar. The results showed that IAA concentrations reached 3,569.32 \pm $85.28 \mathrm{mg} / \mathrm{L}$ after 4 days, corresponding to an IAA yield of $0.66 \mathrm{mg} / \mathrm{mg}$ L-tryptophan (Fig. 6), when the $\mathrm{V}_{\text {tip }}$ value was kept constant at $6.96 \mathrm{~m} / \mathrm{s}$ (corresponding to an agitation speed of $170 \mathrm{rpm}$ ).

Cost efficiency is always a key factor in the industrialization of products. An increase in IAA productivity will obviously reduce the overall production cost and, hence, the cost of the product. This study showed that the highest IAA production was obtained when low-cost substrates, i.e., crude glycerol, CSL and feedgrade L-tryptophan, were used. The production cost per liter of the optimal medium obtained via the RSM approach was 2.10 USD per liter, while the original medium (YPD broth) cost 7.61 USD per liter, as shown in Table 2. This means that IAA production by $R$. fluvialis DMKU-CP293 in the optimal medium provided an effective cost reduction of 3.6-fold. Based on the production scale of the bioreactors, 2-L, 15-L and 100 -L production cost $0.74,0.60$ and 0.60 USD per gram IAA, respectively. 
Table 2

Cost of IAA production medium in $100 \mathrm{~L}$ bioreactor

\begin{tabular}{|lll|}
\hline Production medium & $\begin{array}{l}\text { Production cost per } \\
\text { L }\end{array}$ & $\begin{array}{l}\text { Obtained } \\
\text { IAA } \\
\text { (mg IAA/L) }\end{array}$ \\
\hline $\begin{array}{l}\text { YPD broth }+0.1 \% \text { analytical-grade L-tryptophan (shaking } \\
\text { flask) }\end{array}$ & 7.61 & $1,061.97$ \\
\hline Optimized IAA production medium & 2.10 & $3,569.32$ \\
\hline
\end{tabular}

\section{Evaluation of IAA as a weed control agent}

This part of the study aimed to evaluate the effect of IAA on weed growth inhibition. Nutgrass (Cyperus rotundus $\mathrm{L}$.) tubers were grown for 15 days in a plastic planting bag with sterile soil to test weed germination. To imitate farmland management practices prior to the planting of a main crop, 15-day-old weed shoots were discarded, and the remaining underground weed tubers were treated with three concentrations of crude IAA (50, 250 or $1,250 \mathrm{mg} / \mathrm{L}$ ), the IAA production medium or sterile distilled water (control). After 9 days of treatment, weed shoot growth was recorded. The growth of weeds treated with the IAA production medium was not significantly different $(p<0.05)$ from that of weeds treated with the control (Fig. 7a). This result indicates that the IAA production medium had no effect on weed growth. Crude IAA significantly suppressed $(p<0.05)$ weed shoot growth compared with the control and medium treatments. At 50,250 and $1,250 \mathrm{mg} / \mathrm{L}$ of crude IAA, weed shoot growth was $65,57.86$ and $55 \%$ of that in the control, indicating inhibitory effects of $30.53,38.17$ and $41.22 \%$, respectively (Fig. $7 \mathrm{a}$ ). Weed shoot length was evidently reduced by $1,250 \mathrm{mg} / \mathrm{L}$ crude IAA compared to that in the water and IAA production medium treatments (Fig. 7b). Overall, the results suggest that crude IAA at least $50 \mathrm{mg} / \mathrm{L}$ may suppress nutgrass growth.

\section{Discussion}

The phylloplane is the surface or aboveground parts of plants and has been recognized as an important habitat for microorganisms ${ }^{30}$. Many phylloplane yeasts have shown the ability to synthesize plant developmental hormones ${ }^{14,24,31-33}$. In the present study, the corn phylloplane yeast $R$. fluvialis DMKUCP293 produced the highest amount of IAA, 3,514.44 mg/L, when cultured in an IAA production medium containing crude glycerol, CSL and feed-grade L-tryptophan as the carbon, nitrogen, and IAA precursor sources, respectively, in a shaking flask. Low-cost substrates were used in this work. The impurities contained in crude glycerol (methanol, $\mathrm{NaOH}$, esters and sulfur compounds) may affect yeast growth; however, crude glycerol and pure glycerol promoted similar levels of IAA production by $R$. fluvialis DMKUCP293. This is probably due to the residual proteins and minerals ${ }^{34}$ in crude glycerol that may support yeast IAA production. Feed-grade L-tryptophan, which was used as a precursor for IAA synthesis, played a major role in reducing IAA production costs, as reported in Nutaratat and Srisuk ${ }^{35}$. In addition, $R$. fluvialis DMKU-CP293 showed a high IAA yield when CSL was provided in the production medium as a nitrogen 
source. This result is consistent with that of Nutaratat, et al. ${ }^{24}$, who indicated that Rhodosporidium paludigenum DMKU-RP301 also exhibited peak IAA production $(314.8 \mathrm{mg} / \mathrm{L})$ when CSL was used as a nitrogen source. CSL is a major byproduct of cornstarch processing and is a low-cost source of proteins, amino acids, minerals and vitamins. It has been reported to be a potential nitrogen source for the production of bioproducts ${ }^{36-39}$. The optimized medium developed in this study (containing crude glycerol, CSL, and feed-grade L-tryptophan) was more cost-effective than other media and achieved high IAA production with a less-expensive fermentation medium. Several low-cost substrates for IAA production have been studied, such as agroindustrial residues, agrowaste substrates, jatropha seedcake, and sweet whey, but the cost of using these substrates has not yet been estimated ${ }^{40-44}$. As shown in Table 2, the fermentation costs of using the initial and optimized medium in the 100-L bioreactor were compared. The total fermentation costs of IAA production medium per liter using the initial and optimized media were 7.61 USD and 2.10 USD, respectively. The low-cost medium developed for IAA production with $R$. fluvialis DMKU-CP293 may facilitate process optimization for economical IAA production at the industrial scale.

R. fluvialis DMKU-CP293 showed high IAA production within only 4 days of fermentation, which could minimize production costs in terms of short-term fermentation. Compared to the production periods in other studies, the yeast $R$. fluvialis DMKU-CP293 required a short IAA production period. Nutaratat, et al. 24 reported high IAA levels generated by the yeast $R h$. paludigenum DMKU-RP301 after 7 days of fermentation, whereas Colletotrichum fructicola CMU-A109 took 26 days to produce its maximum IAA concentration ${ }^{16}$. In addition to medium components, fermentation temperature is another parameter to consider. Our studies showed high IAA production at $34^{\circ} \mathrm{C}$, which is slightly higher than the ordinary yeast growth temperature. Applying this temperature would help to somewhat reduce cooling costs for IAA production in tropical countries, including Thailand.

In the current study, IAA optimization was carried out by a combination of the OFAT and RSM approaches. The results from the medium optimized by RSM ultimately provided a high IAA yield that was 3.3-fold higher than that of the non-optimized medium. RSM is a statistical optimization method that has been successfully applied by many researchers to improve IAA production $21,24,44,45$. RSM allows more factors to be evaluated at the same time for their effects on IAA production than the OFAT approach and provides less variability in the experiments. In addition, the interactions between factors can be estimated systematically when using RSM, but they cannot be estimated by OFAT ${ }^{46}$. The results obtained in the present work are consistent with the report of Nutaratat, et al. ${ }^{24}$, which determined the final optimal conditions for IAA production using RSM after the OFAT approach. In addition, we also found that yeast extract did not enhance IAA production by this yeast, possibly because the CSL provided enough growth factors ${ }^{47,48}$ for IAA production.

High-quantity production is a key factor in successful industrial bioprocesses. Fermentation was scaled up to a 15-L bioreactor in this work on the basis of the optimum conditions identified in a 2-L bioreactor. The experiment aimed to obtain cell and product quantities at a large scale (the industrial or pilot-plant 
scale) with at least the same efficiency as that obtained at a laboratory scale. However, upscaling is not an easy task because different reduction foam efficiencies, substrate bioavailability levels, oxygen transfer efficiencies and adverse physical or biological effects can occur at different fermentation scales 49.

For bioproduction processes involving aeration, the biomass yield and growth-associated products have been shown to decrease when performed at a large scale ${ }^{50}$. Our research revealed that batchfermentation IAA production reached 3,468.17 $\pm 66.61 \mathrm{mg} / \mathrm{L}$ in the 15 - $\mathrm{L}$ reactor, representing a yield of $0.68 \mathrm{~g} \mathrm{IAA} / \mathrm{g}$ L-tryptophan, which is the highest production ever reported by yeast ${ }^{51}$. Complete Ltryptophan consumption by $R$. fluvialis DMKU-CP293 was shown after 2 days of fermentation, suggesting that batch-fed fermentation may help to avoid inefficiencies in the L-tryptophan supply and hence incomplete IAA production. Surprisingly, higher IAA production was found in the 15-L bioreactor than in the 2-L bioreactor. This may be due to differences in the bioreactor design, such as in the impeller spacing, baffle and sparger specifications, and vessel ratio, which helped to provide better yeast growth and IAA production in the 15-L bioreactor than in the 2-L bioreactor. In 2015, Shivanandappa, et al. ${ }^{52}$ reported that impeller position affected the growth yield of Bordetella pertussis strain 509 during largescale batch fermentation. A single impeller was found to improve the growth yield of $B$. pertussis strain 509 , whereas two and three impellers located at various positions resulted in a decrease in the growth rate due to the disturbance of vortex flows and broth mixing resulting in less dissolved oxygen being transferred.

Tip velocity $\left(V_{\text {tip }}\right)$ is another useful parameter for increasing the production size to the pilot or industrial scale ${ }^{53-55}$. $V_{\text {tip }}$ was shown to be an effective parameter for IAA production by R. fluvialis DMKU-CP293 in a pilot-scale 100-L bioreactor. Based on the $V_{\text {tip }}$ scaling-up strategy, this research revealed a similar level of IAA production in a 100-L bioreactor to those obtained in a shaking flask and a laboratory-scale 15-L bioreactor. This is the first report of microbial IAA production in a pilot-scale bioreactor using low-cost substrates, i.e., crude glycerol, CSL, and feed-grade L-tryptophan. All results suggested that the optimized medium obtained in this study could be used as a cost-effective medium for IAA production by $R$. fluvialis DMKU-CP293 at the industrial scale.

The development of biological products that can be used for eco-friendly agriculture is urgently required to reduce environmental pollution due to the current excessive use of harmful agrochemicals. IAA can have both positive and negative effects on plants depending on the dosage used and the plant species. The application of IAA at low levels (approximately $1 \mathrm{nmol} / \mathrm{L}-10 \mu \mathrm{g} / \mathrm{L}$ ) was reported to promote plant growth ${ }^{43,56}$, but higher amounts of IAA showed adverse effects on plant growth ${ }^{57}$. Our research attempted to harness the adverse effects of IAA to control weed growth. Cyperus rotundus L., nutgrass, shows rapid growth and good tolerance to several stress conditions, including drought. This grass is truly difficult to remove from land and farms because its tubers remain underground after land development and prior to plantation. It usually grows along with or overtakes the growth of main crops due to its drought tolerance and recovers to grow immediately in the rainy season or after crop watering. This grass 
has therefore been considered to be the world's worst weed ${ }^{58}$. This grass can be killed or inhibited by chemical herbicides such as glyphosate and paraquat; the residues of these herbicides are well known to cause environmental pollution and are harmful to human health. The inhibitory effect of IAA could be exploited to allow its use as an alternative herbicide due to its negative effect on plant growth when applied at high concentrations. The application of high-load IAA as a bioherbicide does not affect crops since IAA degrades under high light intensities ${ }^{59}$. The results revealed that $50 \mathrm{mg} / \mathrm{L}$ showed an inhibitory effect on the growth of the weed Cyperus rotundus $L$. This is consistent with the report of Dahiya, et al. ${ }^{60}$, which showed an inhibitory effect of bacterial IAA at $53.80 \mu \mathrm{g} / \mathrm{mL}$ on Avena fatua (wild oat). At a high IAA concentration $(1,250 \mathrm{mg} / \mathrm{L})$, shoot growth was evident. This observation was consistent with the study of Cline ${ }^{61}$ reporting that $1 \%$ exogenous IAA (equivalent to $10,000 \mathrm{mg} / \mathrm{L}$ ) significantly inhibited lateral bud outgrowth in the tested plant species (Ipomoea nil, Helianthus annuus, Lycopersicon esculentum (VNF8), Pisum sativum). In another study, Kim and $\mathrm{Krcmcr}^{62}$ reported that Bradyrhizobium japonicum GD3 and Pseudomonas putida GD4 produced high IAA concentrations of $64 \mathrm{mM}$ and $6.9 \mathrm{mM}$ (equivalent to $11,210 \mathrm{mg} / \mathrm{L}$ and $1,210 \mathrm{mg} / \mathrm{L}$, respectively) that significantly reduced the growth of morning glory (Ipomoea spp.). Research on bioherbicides should be attracting broad interest due to bans on certain agrochemicals and environmental concerns related to farmer health. Moreover, the development of product formulations with longer shelf lives is required for successful commercialization.

\section{Materials And Methods}

\section{Microorganism and cultivation medium}

The corn phylloplane yeast Rhodosporidiobolus fluvialis DMKU-CP293 (LC379571) was grown on yeast extract peptone dextrose (YPD) agar (1\% yeast extract, $2 \%$ peptone, $2 \%$ glucose and $1.5 \%$ agar). Yeast inoculum was cultivated in $50 \mathrm{~mL}$ of YPD broth and incubated on an orbital shaker (JS Research Inc., South Korea) at $170 \mathrm{rpm}$ and $30^{\circ} \mathrm{C}$ for $16-18 \mathrm{hr}$. The yeast cells were collected by centrifugation for 5 min at 10,000 $\times g$, washed twice with sterilized distilled water, and transferred into a $250 \mathrm{~mL}$ Erlenmeyer flask containing $50 \mathrm{~mL}$ of YPD medium supplemented with $0.1 \%(\mathrm{w} / \mathrm{v})$ L-tryptophan. The medium initial $\mathrm{pH}$ was adjusted to 6 , and the initial optical density at $600 \mathrm{~nm}\left(\mathrm{OD}_{600}\right)$ was adjusted to 0.2 prior to incubation on an orbital shaker at $200 \mathrm{rpm}$ and $30^{\circ} \mathrm{C}$. Samples were taken every $24 \mathrm{~h}$. The culture broth was collected by centrifugation for $5 \mathrm{~min}$ at $10,000 \times \mathrm{g}$, and then the supernatant was analyzed for its IAA concentration by high-performance liquid chromatography (HPLC).

\section{Medium optimization in shake-flask cultivation}

\section{Experimental design for optimizing IAA production using low-cost substrates}

\section{One-factor-at-a-time (OFAT)}


The OFAT approach was applied to preliminarily screen for influencing factors using YPD as the base medium. Various nutritional conditions were studied: different carbon sources (galactose, glucose, lactose, sucrose, glycerol, and xylose), crude glycerol concentrations $(0-5 \%)$, nitrogen sources $\left(\mathrm{NH}_{4} \mathrm{Cl}\right.$, $\left(\mathrm{NH}_{4}\right)_{2} \mathrm{SO}_{4},\left(\mathrm{NH}_{4}\right)_{2} \mathrm{HPO}_{4}, \mathrm{KNO}_{3}, \mathrm{NaNO}_{3}, \mathrm{NH}_{4} \mathrm{NO}_{3}$, peptone, tryptone, urea, CSL, CSL concentrations (0.05$2 \%)$, growth factor sources (yeast extract, malt extract, and beef extract), technical-grade yeast extract concentrations $(0.05-2 \%)$ and feed-grade L-tryptophan concentrations $(0.1-0.7 \%)$. High-purity glycerol (Ajax Finechem Pty Ltd., Australia), laboratory-grade yeast extract (Becton, Dickinson and Company, USA) and analytical-grade L-tryptophan (Acros Organics, USA) were used in the high-cost medium whereas crude glycerol (Global Green Chemicals Public Company Limited, Thailand), technical-grade yeast extract (Becton, Dickinson and Company, USA) and feed-grade L-tryptophan (Ajinomoto Animal Nutrition Europe, France) were used in the low-cost medium. The initial medium $\mathrm{pH}$ was adjusted to 6 in all experiments. The incubation times $(0-7$ days $)$ and temperatures $\left(30-35^{\circ} \mathrm{C}\right)$ were also optimized. All experiments were performed in triplicate, and the results are reported as the mean of these replications.

\section{Response Surface Methodology (RSM)}

Central composite design (CCD) ${ }^{63}$ was used to identify the optimum conditions for IAA production after the preliminary range of variables was determined through OFAT. The CCD included an embedded factorial or fractional factorial matrix with center points and star points around the center point. The distance from the center of the design space to a factorial point was \pm 1 unit for each factor, and the distance from the center of the design space to a star point was $\pm a$, where $|a|>1$. An axial distance $(+a)$ of 1.68 was chosen to make the design rotatable. The variables included crude glycerol, CSL, technicalgrade yeast extract, and feed-grade L-tryptophan at five coded levels, $-a,-1,0,+1,+a$, which are shown in Table S1. The CCD included 21 experimental trials, with 5 trials as replications of the center points. The results from the CCD were then statistically evaluated by Design Expert 10 software (Stat-Ease Inc., England). All experiments were performed in triplicate, and the results are reported as the mean of these replications.

\section{Batch cultivation of IAA using low-cost substrates in a laboratory-scale bioreactor}

The effects of fermentation parameters such as agitation speed and inoculum size were examined to maximize IAA production using a bench scale 2-L bioreactor (BIOSTAT B, B. Braun Biotech International, Germany) with a 1.5-L working volume. Yeast inoculum was prepared in a $250 \mathrm{~mL}$ Erlenmeyer flask containing $50 \mathrm{~mL}$ YPD broth and then incubated on an orbital shaker (JS Research Inc., South Korea) at $170 \mathrm{rpm}$ and $30^{\circ} \mathrm{C}$ for $24 \mathrm{~h}$. The culture $\mathrm{OD}_{600}$ reached approximately 4.0 . The yeast inoculum was transferred to the IAA production medium obtained in the previous experiment (4.5\% crude glycerol, $2 \%$ CSL and $0.55 \%$ feed-grade L-tryptophan). The process parameters included different agitation speeds (200, 300 and $400 \mathrm{rpm})$ and inoculum sizes (5\%, 10\%, 15\%, and 20\%), and the processes were performed in a 2-L bioreactor for maximum IAA production. The aeration and incubation temperatures were kept constant at $1.5 \mathrm{~L} / \mathrm{min}(1 \mathrm{vvm})$ and $34^{\circ} \mathrm{C}$, respectively. The culture $\mathrm{pH}$ and dissolved oxygen percentage 
were monitored by pH electrodes (405-DPAS-SC-K8S/225, Mettler Toledo, Switzerland) and dissolved oxygen sensor probes (InPro® 6800, Mettler Toledo, Switzerland), respectively.

A stainless steel 15-L stirred tank bioreactor (BIOSTAT C, B. Braun Biotech International, Germany) was used in the scaling-up of the fermentation. The fermentation conditions and optimized IAA production medium obtained from the 2-L bioreactor were applied in the 15- $\mathrm{L}$ bioreactor. The culture $\mathrm{pH}$ was measured offline by a benchtop pH meter equipped with a pH electrode LE438 (FiveEasy ${ }^{\mathrm{TM}}$ F20, Mettler Toledo, Switzerland). Samples were taken daily for 7 days and centrifuged $(10,000 \times g$ for $5 \mathrm{~min})$ to collect the supernatant prior to IAA analysis by HPLC. The experiment was performed twice.

\section{Pilot-scale IAA production in a 100-L bioreactor}

Pilot-scale batch culture was carried out in a 100-L stirred tank model MPF-U2W (B.E. MARUBISHI Co., Ltd., Japan). The impeller tip velocity $\left(V_{\text {tip }}\right)$ was focused on as a scaling-up parameter and was calculated as described in Wang, et al. ${ }^{64}$

and Eq. (2): $\mathrm{V}_{\text {tip }}=2 \pi N D_{1}(2)$

where $V_{\text {tip }}$ is the impeller tip speed, $N$ is the agitation speed, and $D_{1}$ is the impeller diameter. The first seed culture was prepared in a 1,000 mL Erlenmeyer flask containing $250 \mathrm{~mL}$ YPD broth in the same manner as previously described. For the scaled-up culture, $500 \mathrm{~mL}$ of the first seed culture was inoculated into a $15-\mathrm{L}$ bioreactor containing $5.5 \mathrm{~L}$ of YPD medium and cultivated for $24 \mathrm{~h}$ at $30^{\circ} \mathrm{C}$ at $200 \mathrm{rpm}$ and $1 \mathrm{vvm}$. Six liters of the second seed culture obtained from the 15-L bioreactor was transferred to the $100-\mathrm{L}$ bioreactor containing $54 \mathrm{~L}$ of production medium obtained from the previous experiment $(4.5 \%$ crude glycerol, $2 \% \mathrm{CSL}$ and $0.55 \%$ feed-grade L-tryptophan) and cultivated for 5 days at $34^{\circ} \mathrm{C}$ with $1 \mathrm{vvm}$ of aeration and $170 \mathrm{rpm}$ of agitation. Samples were taken daily and centrifuged (10,000 $\times g$ for $5 \mathrm{~min}$ ), and the supernatant was collected and analyzed for its IAA concentration by HPLC. The culture $\mathrm{pH}$ was measured offline by a benchtop pH meter equipped with a LE438 pH electrode. The experiment was performed twice.

\section{Assessment of the inhibitory effect of IAA on weed growth}

Tubers of Cyperus rotundus $\mathrm{L}$. were collected from Suan Kaset Insee, a local farm in Chonburi province, Thailand. Seven tubers of Cyperus rotundus L. were grown in plastic planting bags (size: 5 inches $\times 10$ inches) filled with sterilized soil in a greenhouse for 15 days for the weed shoot germination test. The weed shoots were cut down prior to being treated every other day with the culture supernatant (crude IAA) at amounts equivalent to 50,250 , and $1,250 \mathrm{mg}$ IAA/L. Sterilized distilled water and the IAA production medium were applied as controls. The amount of shoot growth was recorded after 9 days. All plant experiments were performed in accordance with relevant guidelines and regulations.

\section{Analytical methods \\ Cell dry weight}


Yeast cell growth was determined by measuring the optical density at $600 \mathrm{~nm}\left(\mathrm{OD}_{600}\right)$ using a spectrophotometer (Genesys 20, Thermo Spectronic, USA). The $\mathrm{OD}_{600}$ was converted to cell dry weight $(\mathrm{CDW})$ using a calibration curve $\mathrm{CDW}(\mathrm{g} / \mathrm{L})=\mathrm{OD}_{600} / 1.5057$

\section{IAA concentration measurement using HPLC}

The culture supernatant was collected by centrifugation for 5 min at 10,000 $\times g$ and analyzed by an HPLC (Agilent Technologies, USA) equipped with a Cosmosil SC18-MS-II column (Nacalai Tesque, Japan) and UV detector (Agilent Technologies, USA) at $280 \mathrm{~nm}$. The mobile phase contained solution A (methanol: acetic acid: water; 10:0.3:89.7 v/v/v) and $60 \%$ solution $B$ (methanol: acetic acid: water; 90:0.3:9.7 v/v/v) at a flow rate of $0.3 \mathrm{~mL} / \mathrm{min}$ as described by Nutaratat, et al. ${ }^{24}$. Isocratic elution was used instead of gradient elution. Authentic IAA (Sigma, USA) was used as a standard.

\section{Statistical Analysis}

The statistical significance of the results was evaluated by one-way analysis of variance (ANOVA) using IBM SPSS version 16 (SPSS, Cary, USA), and the individual comparisons were evaluated with Duncan's multiple range test (DMRT). A value of $p<0.05$ was considered to indicate a significant difference between treatments.

\section{Declarations}

\section{Acknowledgements}

This work was supported by the Thailand Research Fund through the TRF Research-Team Promotion Grant (RTA608004), Kasetsart University Research and Development Institute (KURDI) grant no. FF(KU)18.64, the Royal Golden Jubilee PhD programme grant no. PHD/0125/2559, Thailand. We would like to thank UGSAS-GU via the "Microbiology Laboratory Station for IC - GU12" at Kasetsart University and International SciKU Branding (ISB), Faculty of Science, Kasetsart University. Authors would also like to thank Miss Dararut Sorndee, Suan Kaset Insee Farm owner, for providing us tubers of Cyperus rotundus $\mathrm{L}$.

\section{Author contributions}

S.B. conducted most of the experiments, data collection and interpreted the data and wrote the manuscript; N.T. participated in experiments and prepared materials described in the work; S.L. revised the manuscript; N.S. supervised the study and revised the manuscript.

\section{Competing interests}

Conflict of interest: The authors declare that there are no conflicts of interest.

Ethical approval: This article does not contain any studies with human participants or animals performed by any of the authors. 


\section{References}

1. Gharde, Y., Singh, P. K., Dubey, R. P. \& Gupta, P. K. Assessment of yield and economic losses in agriculture due to weeds in India. Crop Prot. 107, 12-18

https://doi.org/10.1016/j.cropro.2018.01.007 (2018).

2. Oerke, E. C. Crop losses to pests. The Journal of Agricultural Science. 144, 31-43 https://doi.org/10.1017/S0021859605005708 (2006).

3. Délye, C. Weed resistance to acetyl coenzyme A carboxylase inhibitors: an update. Weed Sci. 53, 728-746 https://doi.org/10.1614/WS-04-203R.1 (2005).

4. Yasuor, H., TenBrook, P. L., Tjeerdema, R. S. \& Fischer, A. J. Responses to clomazone and 5ketoclomazone by Echinochloa phyllopogon resistant to multiple herbicides in Californian rice fields. Pest Manag. Sci. 64, 1031-1039 https://doi.org/10.1002/ps.1604 (2008).

5. Bailey, K. L. in Integrated Pest Management (ed Dharam P. Abrol) Ch. 13, 245-266(Academic Press, 2014).

6. Cleland, R. E. in Plant hormones and their role in plant growth and development (ed Davies Peter) 132-148(Springer, 1987).

7. Rayle, D. L. \& Cleland, R. E. The acid growth theory of auxin-induced cell elongation is alive and well. Plant physiology. 99, 1271-1274 (1992).

8. Ludwig-Müller, J., Jülke, S., Bierfreund, N. M., Decker, E. L. \& Reski, R. Moss (Physcomitrella patens) GH3 proteins act in auxin homeostasis. New phytologist. 181, 323-338 (2009).

9. Sindhu, S. S. \& Sehrawat, A. in Microorganisms for Green Revolution: Volume 1: Microbes for Sustainable Crop Production (eds Deepak G. Panpatte, Yogeshvari K. Jhala, Rajababu V. Vyas, \& Harsha N. Shelat) 391-430(Springer Singapore, 2017).

10. Sindhu, S. S., Khandelwal, A., Phour, M. \& Sehrawat, A. in Role of Rhizospheric Microbes in Soil: Volume 1: Stress Management and Agricultural Sustainability (ed Vijay Singh Meena) 331376(Springer Singapore, 2018).

11. Park, J. M., Radhakrishnan, R., Kang, S. M. \& Lee, I. J. IAA producing Enterobacter sp. I-3 as a potent bio-herbicide candidate for weed control: a special reference with lettuce growth inhibition. Indian journal of microbiology. 55, 207-212 https://doi.org/10.1007/s12088-015-0515-y (2015).

12. Skoog, F. Experiments on bud inhibition with indole-3-acetic acid. American Journal of Botany. 26, 702-707 https://doi.org/10.2307/2437018 (1939).

13. Grossmann, K. Auxin herbicides: current status of mechanism and mode of action. Pest Manag. Sci. 66, 113-120 https://doi.org/10.1002/ps.1860 (2010).

14. Limtong, S. \& Koowadjanakul, N. Yeasts from phylloplane and their capability to produce indole-3acetic acid. World Journal of Microbiology and Biotechnology. 28, 3323-3335 https://doi.org/10.1007/s11274-012-1144-9 (2012).

15. Shokri, D. \& Emtiazi, G. Indole-3-acetic acid (IAA) production in symbiotic and non-symbiotic nitrogenfixing bacteria and its optimization by Taguchi design. Curr. Microbiol. 61, 217-225 
https://doi.org/10.1007/s00284-010-9600-y (2010).

16. Numponsak, T., Kumla, J., Suwannarach, N., Matsui, K. \& Lumyong, S. Biosynthetic pathway and optimal conditions for the production of indole-3-acetic acid by an endophytic fungus, Colletotrichum fructicola CMU-A109. PLOS ONE. 13, e0205070 https://doi.org/10.1371/journal.pone.0205070 (2018).

17. Sun, P. F. et al. Indole-3-acetic acid-producing yeasts in the phyllosphere of the carnivorous plant Drosera indica L. PloS one. 9, e114196-e114196 https://doi.org/10.1371/journal.pone.0114196 (2014).

18. Lin, L. \& Xu, X. Indole-3-acetic acid production by endophytic Streptomyces sp. En-1 isolated from medicinal plants. Current microbiology. 67, 209-217 (2013).

19. Ramesh, G., Vedha Hari, B. \& Dhevendaran, K. Microbial association with selected medicinal plants in rhizosphere and their biodiversity. Advances in Natural and Applied Sciences. 6, 947-958 (2012).

20. Nutaratat, P., Srisuk, N., Arunrattiyakorn, P. \& Limtong, S. Plant growth-promoting traits of epiphytic and endophytic yeasts isolated from rice and sugar cane leaves in Thailand. Fungal Biology. 118, 683-694 https://doi.org/10.1016/j.funbio.2014.04.010 (2014).

21. Nutaratat, P., Monprasit, A. \& Srisuk, N. High-yield production of indole-3-acetic acid by Enterobacter sp. DMKU-RP206, a rice phyllosphere bacterium that possesses plant growth-promoting traits. 3 Biotech. 7, 305 (2017).

22. Bunsangiam, S. et al. Biosynthetic pathway of indole-3-acetic acid in basidiomycetous yeast Rhodosporidiobolus fluvialis. Mycobiology. 47, 292-300 (2019).

23. Scarcella, A. S. A., Junior, B., Bastos, R., Magri, M. M. R., Temperature \& R. G. \& pH and carbon source affect drastically indole acetic acid production of plant growth promoting yeasts. Brazilian Journal of Chemical Engineering. 34, 429-438 (2017).

24. Nutaratat, P., Amsri, W., Srisuk, N., Arunrattiyakorn, P. \& Limtong, S. Indole-3-acetic acid production by newly isolated red yeast Rhodosporidium paludigenum. The Journal of General and Applied Microbiology. 61, 1-9 https://doi.org/10.2323/jgam.61.1 (2015).

25. Chandra, S., Askari, K. \& Kumari, M. Optimization of indole acetic acid production by isolated bacteria from Stevia rebaudiana rhizosphere and its effects on plant growth. Journal of Genetic Engineering and Biotechnology. 16, 581-586 https://doi.org/10.1016/j.jgeb.2018.09.001 (2018).

26. Bhutani, N., Maheshwari, R., Negi, M. \& Suneja, P. Optimization of IAA production by endophytic Bacillus spp. from Vigna radiata for their potential use as plant growth promoters. Israel Journal of Plant Sciences. 65, 83 https://doi.org/10.1163/22238980-00001025 (2018).

27. da Rosa, F. A., Rebelo, R. A. \& Nascimento, M. G. Synthesis of new indolecarboxylic acids related to the plant hormone indoleacetic acid IAA. Journal of the Brazilian Chemical Society. 14, 11-15 (2003).

28. Myers, R. H., Montgomery, D. C. \& Anderson-Cook, C. M. Response surface methodology: process and product optimization using designed experiments. (John Wiley \& Sons 2016). 
29. Ferreira, S. L. C. et al. Application of multivariate techniques in optimization of spectroanalytical methods. Applied spectroscopy reviews. 42, 475-491 (2007).

30. Whipps, J. M., Hand, P., Pink, D. \& Bending, G. D. Phyllosphere microbiology with special reference to diversity and plant genotype. J App/ Microbiol. 105, 1744-1755 https://doi.org/10.1111/j.13652672.2008.03906.x (2008).

31. Limtong, S., Kaewwichian, R., Yongmanitchai, W. \& Kawasaki, H. Diversity of culturable yeasts in phylloplane of sugarcane in Thailand and their capability to produce indole-3-acetic acid. World journal of microbiology \& biotechnology. 30, 1785-1796 https://doi.org/10.1007/s11274-014-16027 (2014).

32. Wang, K., Sipilä, T. P. \& Overmyer, K. The isolation and characterization of resident yeasts from the phylloplane of Arabidopsis thaliana. Sci. Rep. 6, 39403 https://doi.org/10.1038/srep39403 (2016).

33. Fu, S. F. et al. Plant growth-promoting traits of yeasts isolated from the phyllosphere and rhizosphere of Drosera spatulata Lab. Fungal Biology. 120, 433-448 https://doi.org/10.1016/j.funbio.2015.12.006 (2016).

34. Anand, P. \& Saxena, R. K. A comparative study of solvent-assisted pretreatment of biodiesel derived crude glycerol on growth and 1,3-propanediol production from Citrobacter freundii. New Biotechnol. 29, 199-205 https://doi.org/10.1016/j.nbt.2011.05.010 (2012).

35. Nutaratat, P. \& Srisuk, N. Low-cost production of indole-3-acetic acid fermentation by Enterobacter sp. CHIANG MAI JOURNAL OF SCIENCE. 46, 653-660 (2019).

36. Lawford, H. G. \& Rousseau, J. D. Corn steep liquor as a cost-effective nutrition adjunct in highperformancezymomonas ethanol fermentations. Applied biochemistry and biotechnology. 63, 287 (1997).

37. Maddipati, P., Atiyeh, H. K., Bellmer, D. D. \& Huhnke, R. L. Ethanol production from syngas by Clostridium strain $\mathrm{P} 11$ using corn steep liquor as a nutrient replacement to yeast extract. Bioresource technology. 102, 6494-6501 (2011).

38. Santos, D. K. et al. Synthesis and evaluation of biosurfactant produced by Candida lipolytica using animal fat and corn steep liquor. Journal of Petroleum Science and Engineering. 105, 43-50 (2013).

39. Kang, C. K., Jeong, S. W., Yang, J. E. \& Choi, Y. J. High-yield production of lycopene from corn steep liquor and glycerol using the metabolically engineered Deinococcus radiodurans R1 strain. Journal of Agricultural and Food Chemistry. 68, 5147-5153 (2020).

40. Swain, M. \& Ray, R. Optimization of cultural conditions and their statistical interpretation for production of indole-3-acetic acid by Bacillus subtilis CM5 using cassava fibrous residue. Journal of Scientific and Industrial Research. 67, 622-628 (2008).

41. Sudha, M. et al. Production and optimization of indole acetic acid by indigenous micro flora using agro waste as substrate. Pakistan Journal of Biological Sciences. 15, 39-43 (2012).

42. Bose, A., Shah, D. \& Keharia, H. Production of indole-3-acetic-acid (IAA) by the white rot fungus Pleurotus ostreatus under submerged condition of Jatropha seedcake. Mycology. 4, 103-111 (2013). 
43. Srisuk, N., Sakpuntoon, V. \& Nutaratat, P. Production of indole-3-acetic acid by Enterobacter sp. DMKU-RP206 using sweet whey as a low-cost feed stock. Journal of microbiology and biotechnology. 28, 1511-1516 (2018).

44. Peng, Y., He, Y., Wu, Z., Lu, J. \& Li, C. Screening and optimization of low-cost medium for Pseudomonas putida Rs-198 culture using RSM. Brazilian Journal of Microbiology. 45, 1229-1237 (2014).

45. Myo, E. M. et al. Indole-3-acetic acid production by Streptomyces fradiae NKZ-259 and its formulation to enhance plant growth. BMC Microbiology. 19, $155 \mathrm{https} / /$ doi.org/10.1186/s12866019-1528-1 (2019).

46. Czitrom, V. One-factor-at-a-time versus designed experiments. The American Statistician. 53, $126-$ 131 (1999).

47. Chiani, M., Akbarzadeh, A., Farhangi, A. \& Mehrabi, M. Production of desferrioxamine B (Desferal) using corn steep liquor in Streptomyces pilosus. Pakistan journal of biological sciences: PJBS. 13, 1151-1155 (2010).

48. Taiwo, A. E., Madzimbamuto, T. N. \& Ojumu, T. V. Optimization of corn steep liquor dosage and other fermentation parameters for ethanol production by Saccharomyces cerevisiae type 1 and anchor instant yeast. Energies. 11, 1740 (2018).

49. Gaikwad, V. et al. Designing of Fermenter and its utilization in food industries. Preprints. https://doi.org/10.20944/preprints201808.0433.v1 (2018).

50. Enfors, S. O. et al. Physiological responses to mixing in large scale bioreactors. Journal of biotechnology. 85, 175-185 (2001).

51. Nutaratat, P., Srisuk, N., Arunrattiyakorn, P. \& Limtong, S. Fed-batch fermentation of indole-3-acetic acid production in stirred tank fermenter by red yeast Rhodosporidium paludigenum. Biotechnology and Bioprocess Engineering. 21, 414-421 https://doi.org/10.1007/s12257-015-0819-0 (2016).

52. Shivanandappa, K. C., Jagannathan, S., Shanmukha, L., Rajendran, V. \& Mani, K. Effect of impeller number and position on growth yield and virulence of Bordetella pertussis strain 509 during large scale batch fermentor cultivation. Asian Journal of Biotechnology. 7, 60-70 (2015).

53. Kim, H. J., Kim, J. H., Oh, H. J. \& Shin, C. S. Morphology control of Monascus cells and scale-up of pigment fermentation. Process Biochem. 38, 649-655 (2002).

54. Kwak, J. K. et al. Optimal criterion for the scale-up production of schizophyllan in the stirred tank reactor. Journal of microbiology and biotechnology. 15, 1-6 (2005).

55. Ha, S. J., Kim, S. Y., Seo, J. H., Oh, D. K. \& Lee, J. K. Optimization of culture conditions and scale-up to pilot and plant scales for coenzyme Q 10 production by Agrobacterium tumefaciens. Applied microbiology and biotechnology. 74, 974-980 (2007).

56. Leveau, J. H. \& Lindow, S. E. Utilization of the plant hormone indole-3-acetic acid for growth by Pseudomonas putida strain 1290. Applied and Environmental Microbiology. 71, 2365-2371 (2005).

57. Contreras-Cornejo, H. A., Macías-Rodríguez, L., Cortés-Penagos, C. \& López-Bucio, J. Trichoderma virens, a plant beneficial fungus, enhances biomass production and promotes lateral root growth 
through an auxin-dependent mechanism in Arabidopsis. Plant physiology. 149, 1579-1592 (2009).

58. Coleman, M., Kristiansen, P., Sindel, B. \& Fyfe, C. Nutgrass (Cyperus rotundus): Weed management guide for Australian vegetable production. (2019).

59. Nissen, S. J. \& Sutter, E. G. Stability of IAA and IBA in nutrient medium to several tissue culture procedures. HortScience HortSci. 25, 800 https://doi.org/10.21273/hortsci.25.7.800 (1990).

60. Dahiya, A., Sharma, R., Sindhu, S. \& Sindhu, S. S. Resource partitioning in the rhizosphere by inoculated Bacillus spp. towards growth stimulation of wheat and suppression of wild oat (Avena fatua L.) weed. Physiology and molecular biology of plants: an international journal of functional plant biology. 25, 1483-1495 https://doi.org/10.1007/s12298-019-00710-3 (2019).

61. Cline, M. G. Exogenous auxin effects on lateral bud outgrowth in decapitated shoots. Annals of Botany. 78, 255-266 (1996).

62. Kim, S. J. \& Krcmcr, R. J. Scanning and transmission electron microscopy of root colonization of morningglory (Ipomoea spp.) seedlings by rhizobacteria.Symbiosis(2005).

63. Box, G. E., Hunter, W. G. \& Hunter, J. S. Statistics for experimenters Vol. 664 (John Wiley, and sons New York, 1978).

64. Wang, D. et al. Translation of laboratory, pilot, and plant scale data. Fermentation and enzyme technology. Wiley, New York,194-211(1997).

\section{Figures}




\section{C-source}

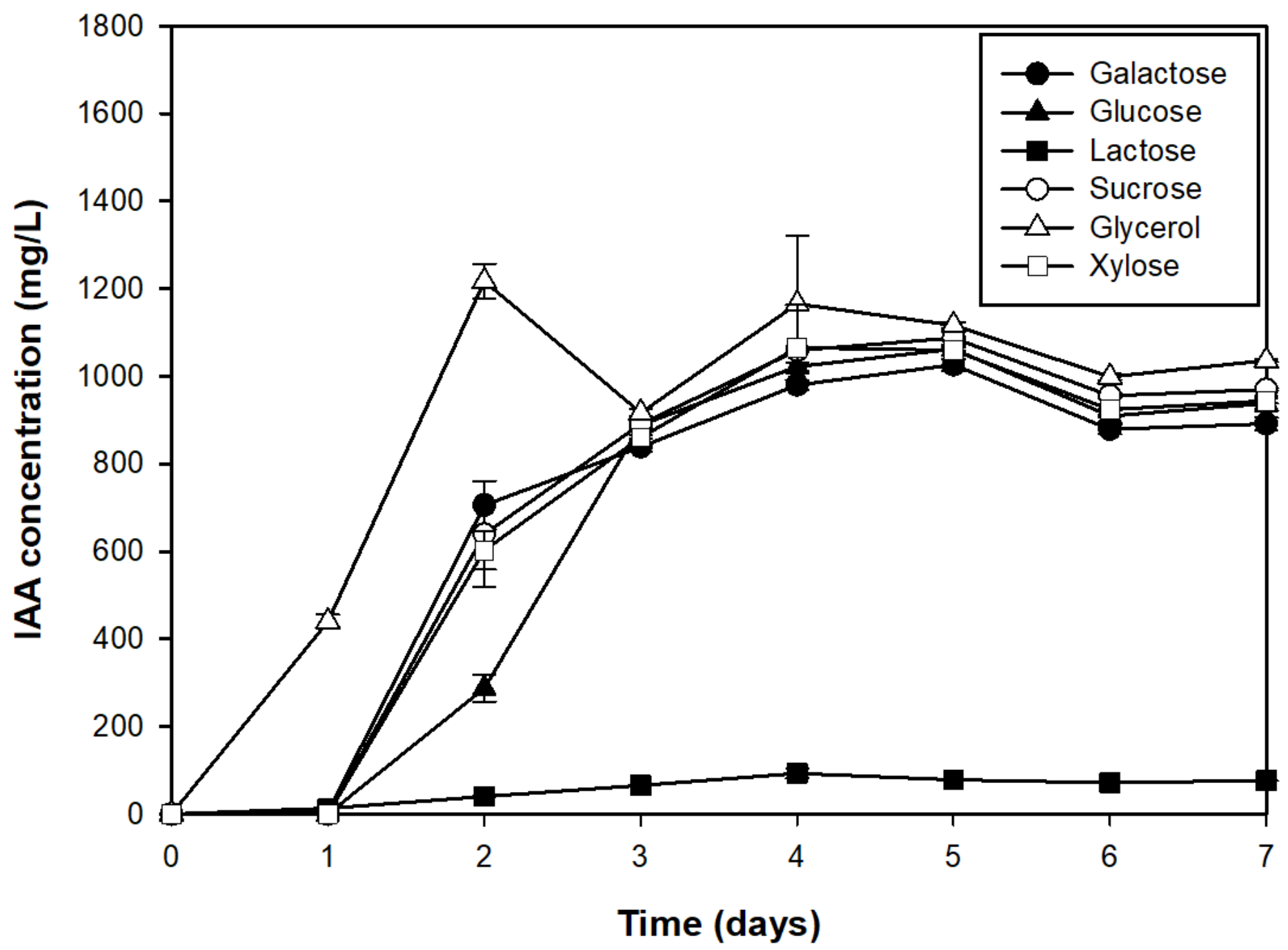

Figure 1

IAA production with various carbon sources by R. fluvialis DMKU-CP293 using YPD base medium ( $2 \%$ carbon source, $2 \%$ peptone, $1 \%$ yeast extract and $0.1 \%$ L-tryptophan) in shake-flask culture at $30{ }^{\circ} \mathrm{C}$ and 200 rpm for 7 days. 

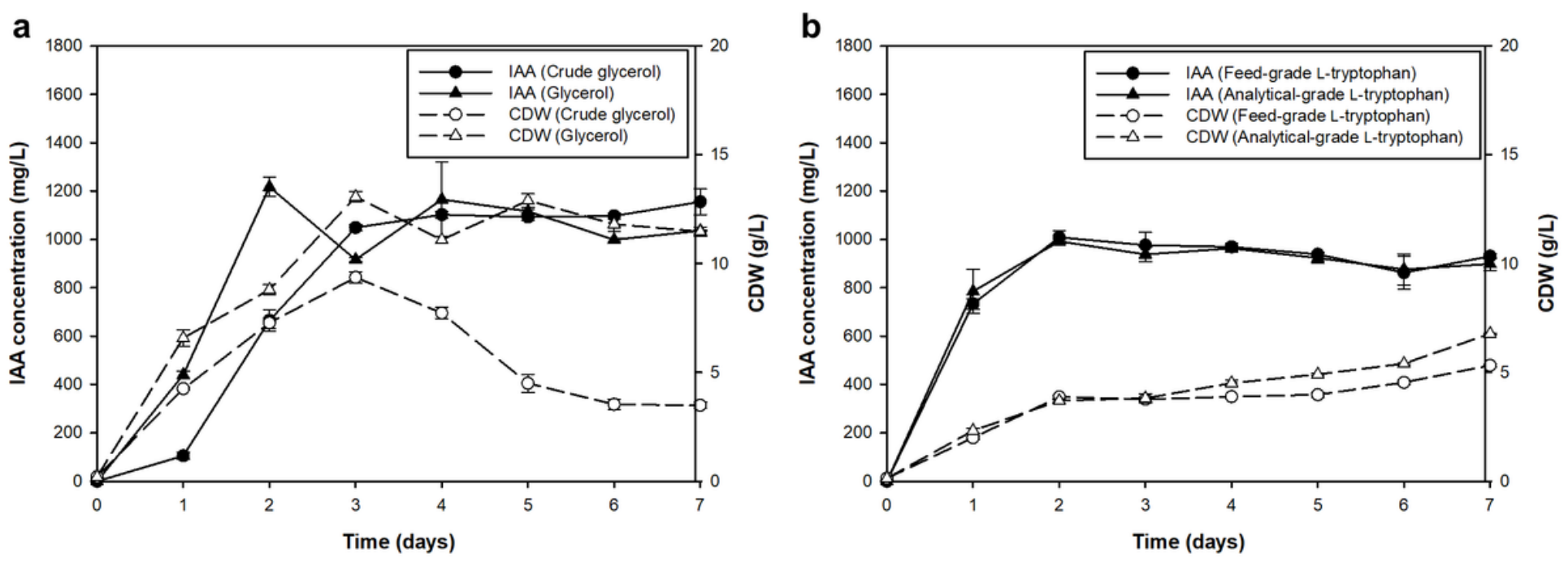

Figure 2

IAA production and cell dry weight of R. fluvialis DMKU-CP293 cultivated in a production medium containing (a) $2 \%$ pure glycerol or crude glycerol, $2 \%$ peptone, $1 \%$ yeast extract and (b) $0.1 \%$ analyticalgrade L-tryptophan or feed-grade L-tryptophan in shake-flask culture at $30^{\circ} \mathrm{C}$ and $200 \mathrm{rpm}$ for 7 days. 

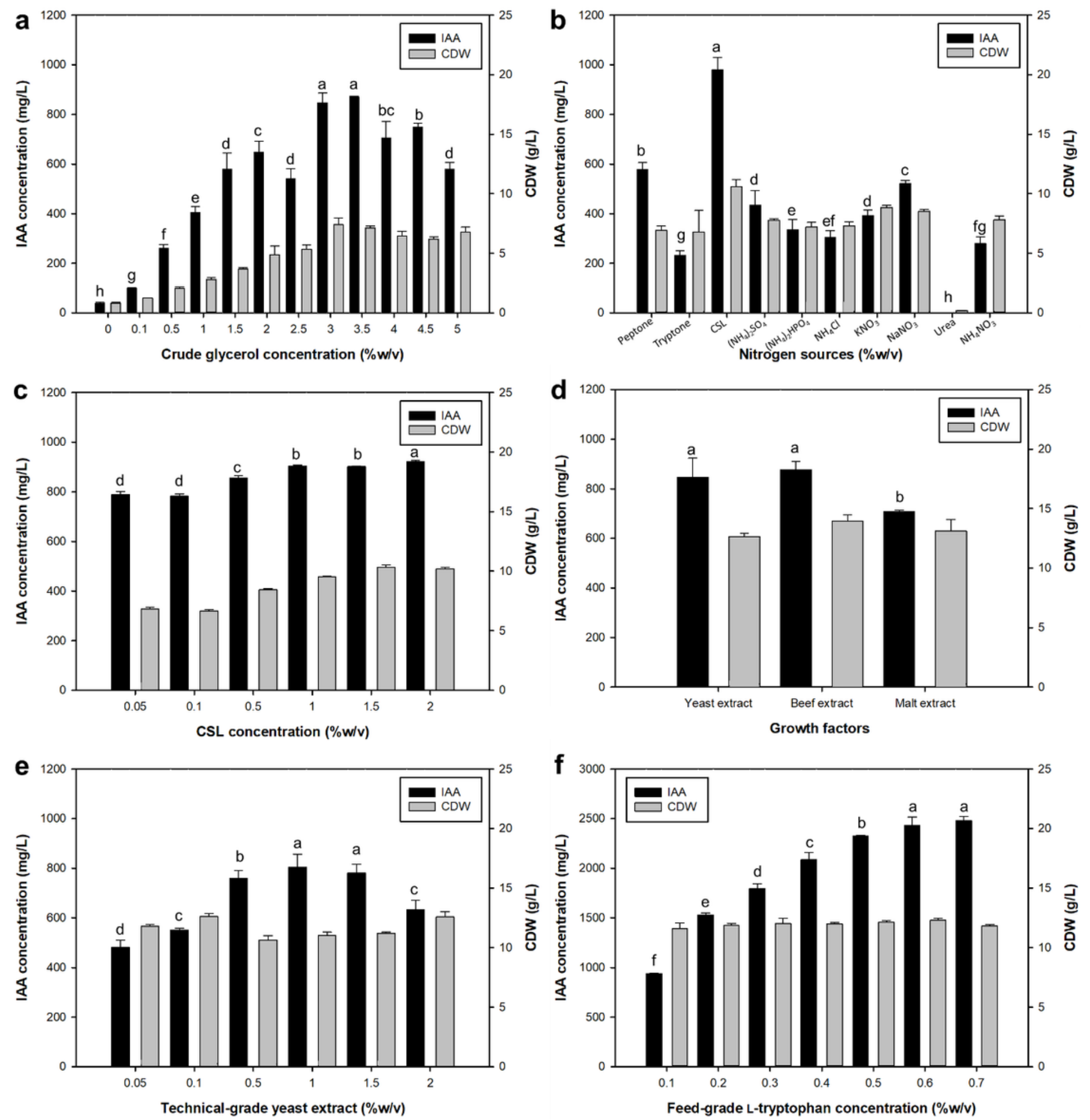

Figure 3

IAA production analyzed using the OFAT approach in media with varying parameters: (a) crude glycerol concentration, (b) nitrogen source, (c) CSL concentration, (d) growth factors, (e) technical-grade yeast extract concentration and (f) feed-grade L-tryptophan concentration at $34^{\circ} \mathrm{C}$ and $200 \mathrm{rpm}$ for 5 days. Different letters over the bars indicate significant differences between treatments using Duncan's multiple range test $(p<0.05)$. 

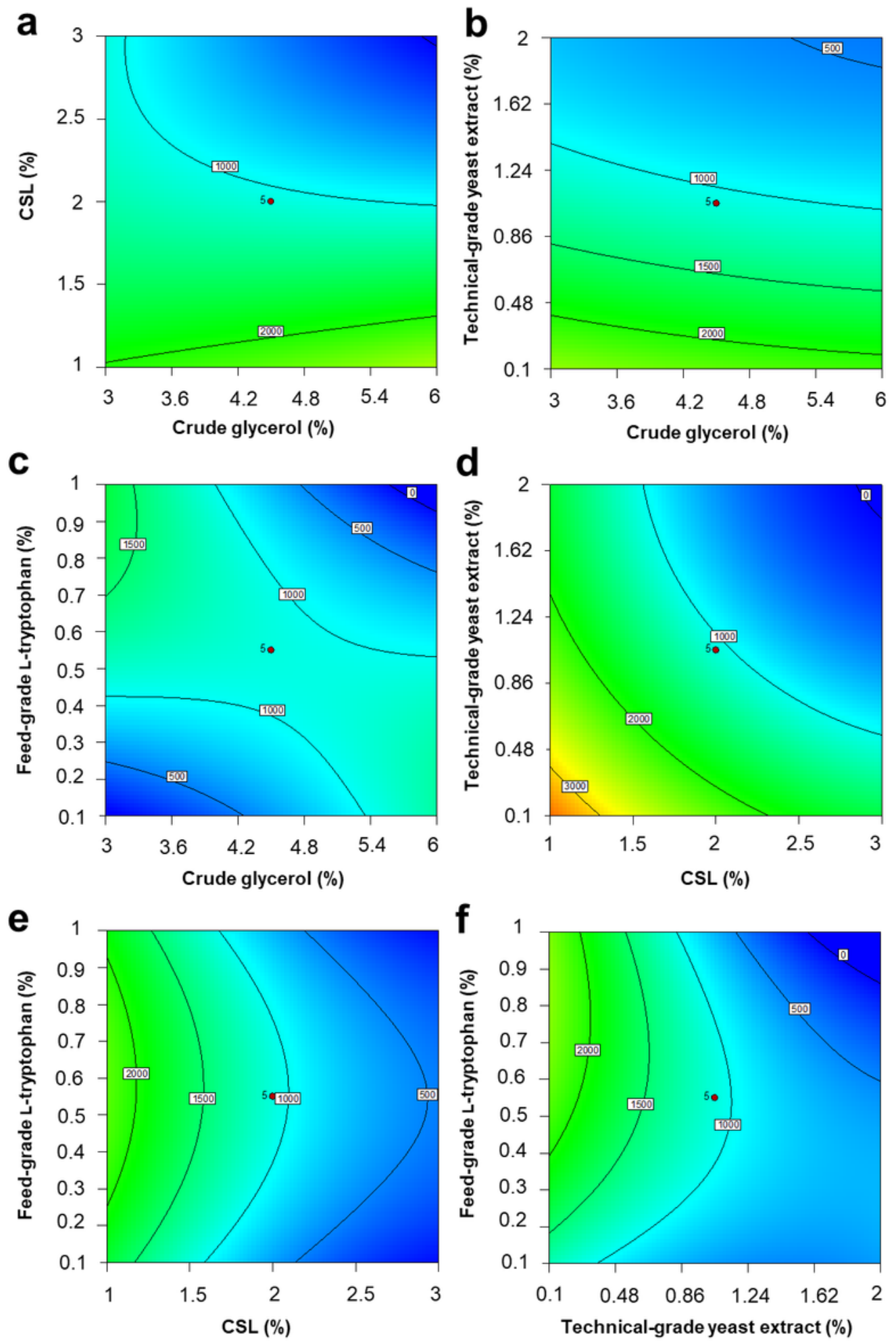

\section{Figure 4}

Contour plots of IAA production by the yeast R. fluvialis DMKU-CP293 using central composite design showing interactions between crude glycerol, CSL, technical-grade yeast extract, and feed-grade Ltryptophan after 5 days of incubation at $200 \mathrm{rpm}$ and $34^{\circ} \mathrm{C}$. 

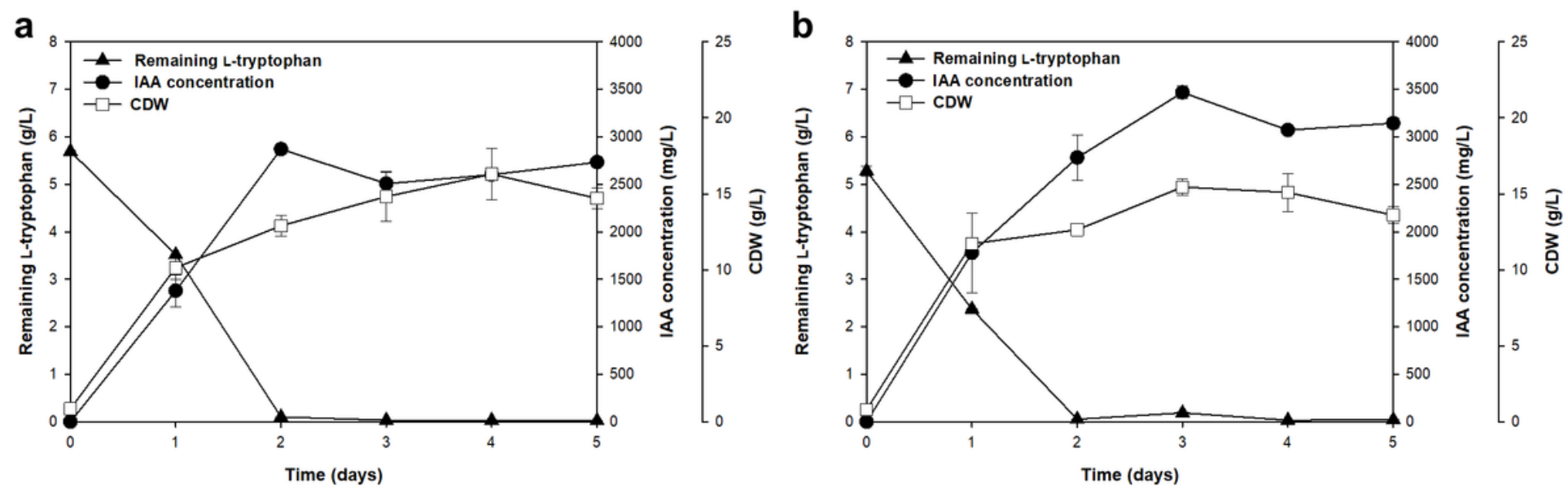

Figure 5

The IAA concentration $(\mathrm{mg} / \mathrm{L})$, remaining L-tryptophan and cell dry weight in the batch fermentation of $\mathrm{R}$. fluvialis DMKU-CP293 in (a) 2-L and (b) 15-L stirred tank bioreactors using the optimal IAA production medium at $34{ }^{\circ} \mathrm{C}$, constant agitation speed (400 rpm), 10\% inoculum size and $1 \mathrm{vvm}$ aeration.

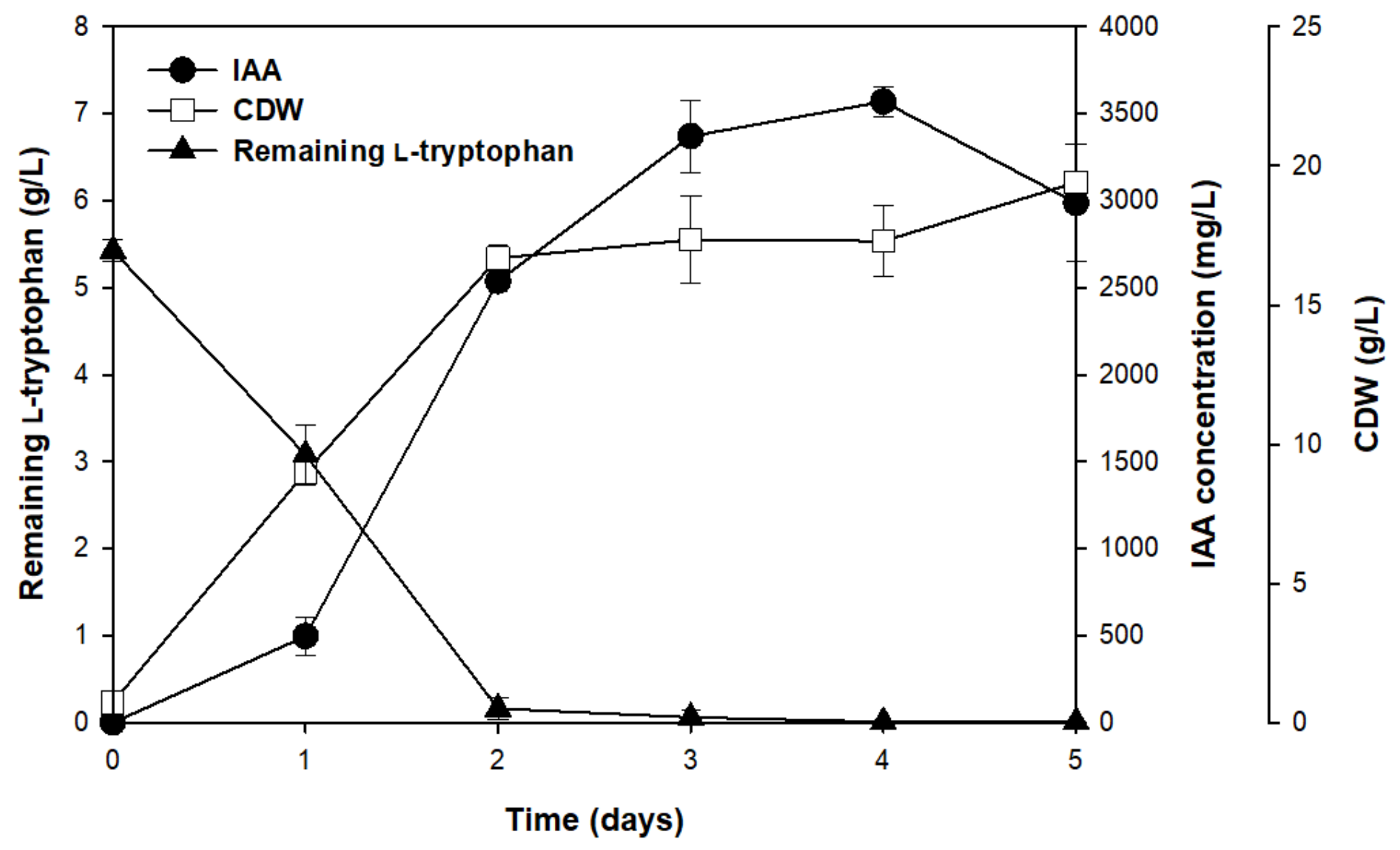

Figure 6

IAA production, L-tryptophan consumption and cell dry weight in batch fermentation by R. fluvialis DMKU$\mathrm{CP} 293$ at the $100-\mathrm{L}$ pilot scale at $34{ }^{\circ} \mathrm{C}$, constant agitation speed (170 rpm), $10 \%$ inoculum size, and 1 
a

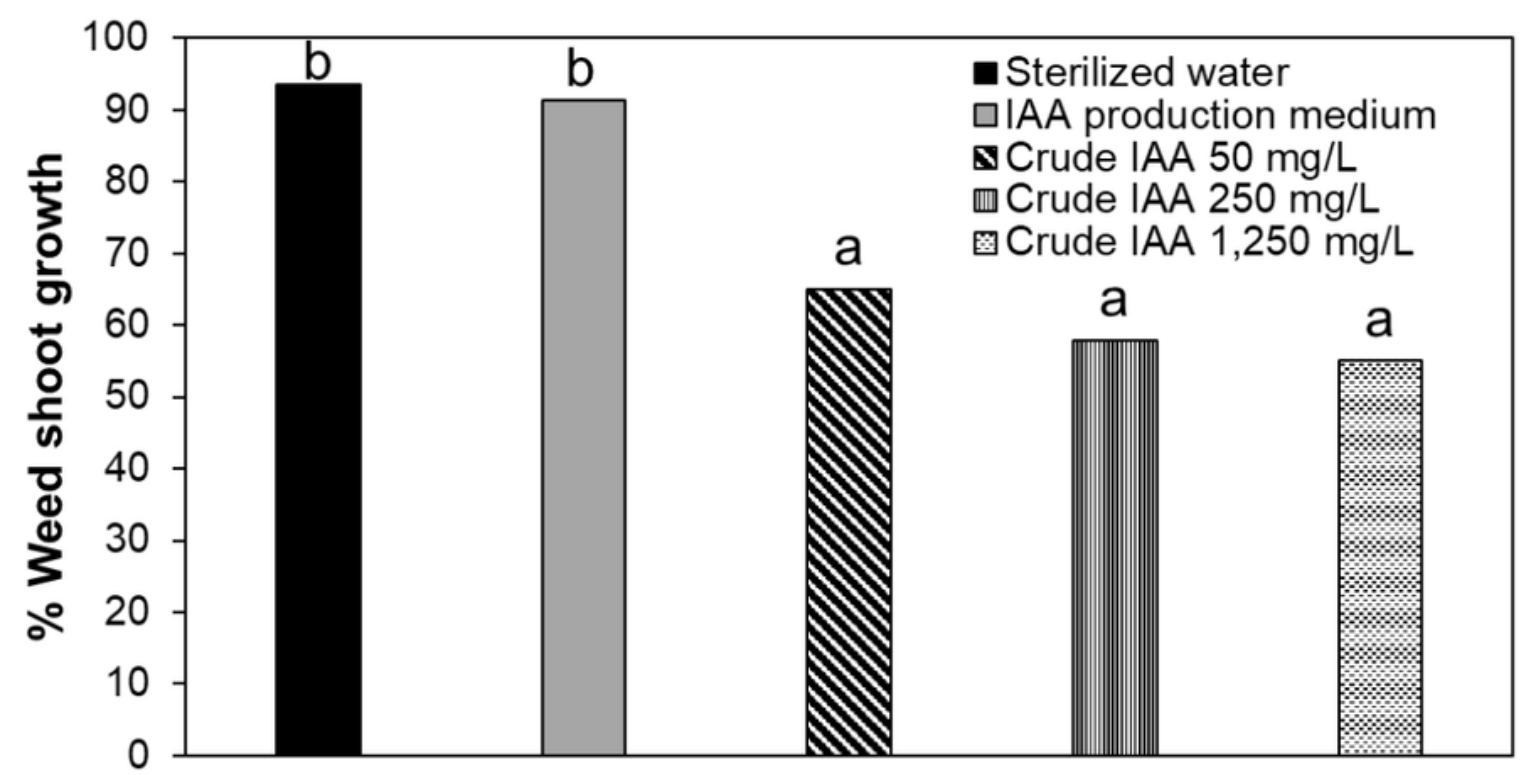

b

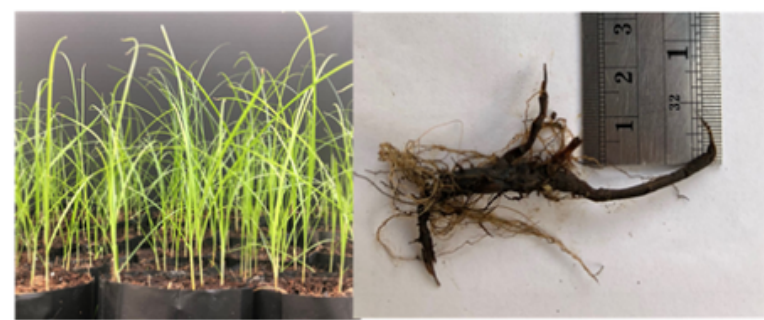

15-day-old weed No shoot growth

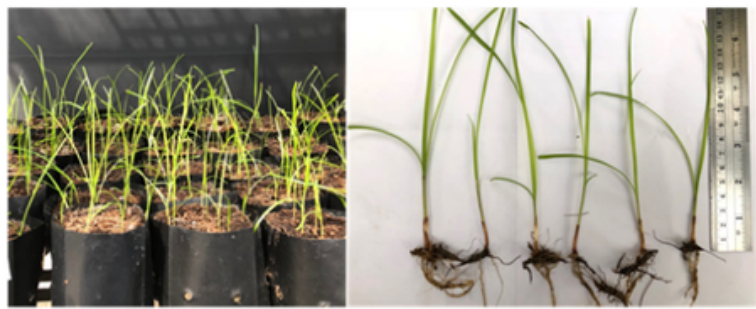

IAA production medium treatment

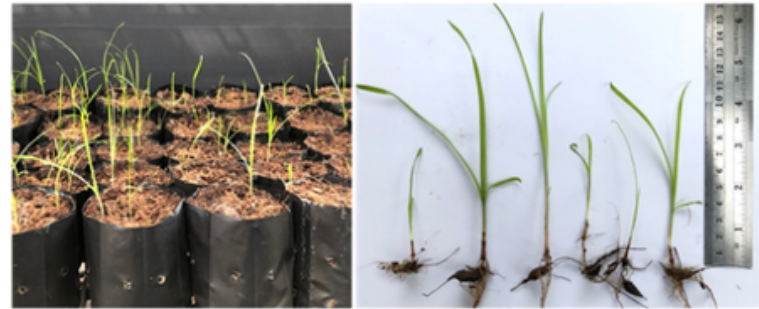

Crude IAA 250 mg/L treatment

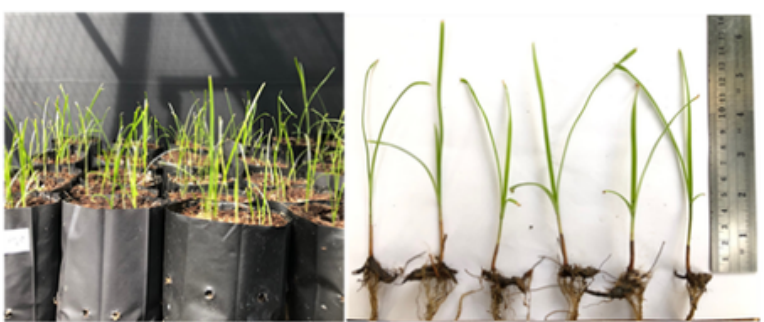

Sterilized water treatment

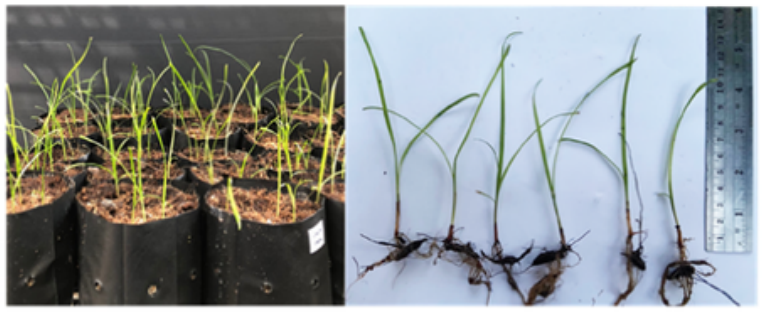

Crude IAA 50 mg/L treatment

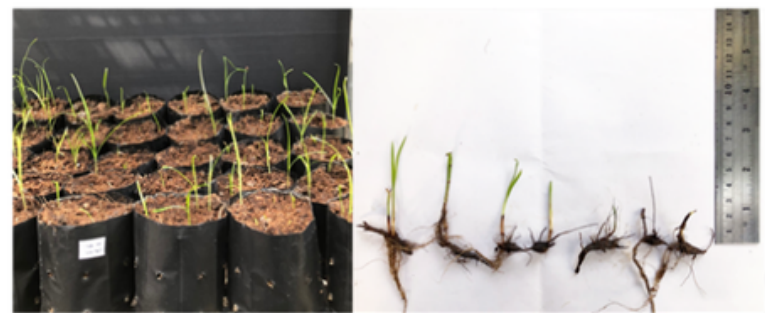

Crude IAA 1,250 mg/L treatment

Figure 7

Effect of (a) crude IAA produced by R. fluvialis DMKU-CP293 on weed shoot growth and (b) weed growth in plastic planting bags in control and crude IAA treatments after 9 days in a greenhouse. Different letters above the bars indicate significant differences between treatments using Duncan's multiple range test $(p<$ 0.05). 


\section{Supplementary Files}

This is a list of supplementary files associated with this preprint. Click to download.

- 210221BunsangiametalSupplementaryDataset.docx 